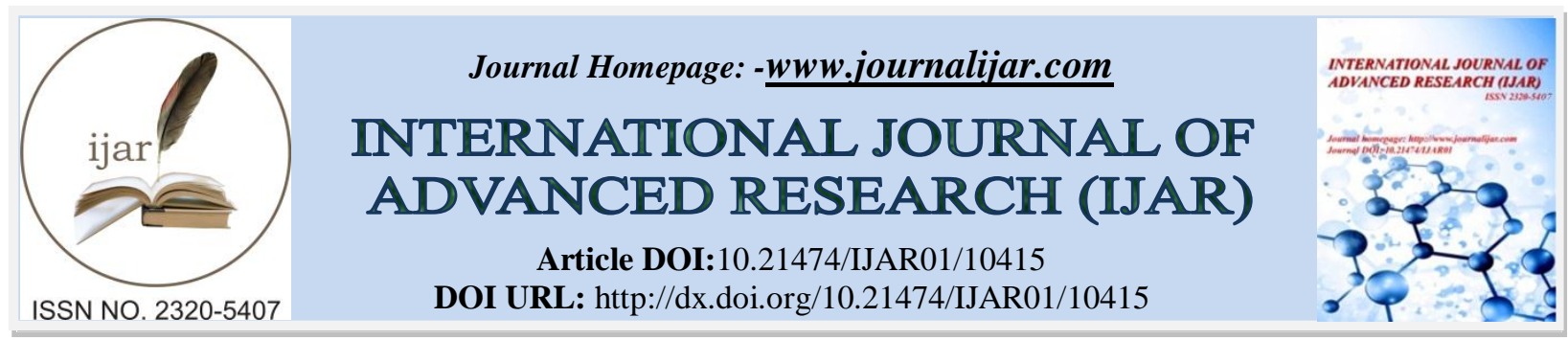

RESEARCH ARTICLE

\title{
PERCEPTUAL MOTOR SKILL DISORDER : A RISKFACTOR FOR LEARNINGPROBLEMS IN ELEMENTARY SCHOOL CHILDREN
}

\author{
Naif Edah Alomairi ${ }^{1}$, Yahea A. Alzahrani ${ }^{2}$, Ola. A. Shawki ${ }^{1}$, Dr. Ayman Abdelbaky ${ }^{3}$, Rahmah Hulayyil M. \\ Alomiry ${ }^{4}$ and Mohammed N. Alazwary ${ }^{5}$ \\ 1. Department of Internal Medicine, College of Medicine, Taif University, Taif, Saudi Arabia. \\ 2. Assistant Professor of Radiology ,Consultant of Radiology, College of Medicine, Taif University, Saudi \\ Arabia. \\ 3. Department of Family And Community Medicine, College of Medicine, Taif University, Taif, Saudi Arabia. \\ 4. Medical Student, College of Medicine, Om Alqura University, Taif, Saudi Arabia. \\ 5. Medical Student, College of Medicine, Imam Mohammad Ibn Saud Islamic University, Taif, Saudi Arabia.
}

\section{Manuscript Info}

\section{Manuscript History}

Received: 30 November 2019

Final Accepted: 31 December 2019

Published: January 2020

Key words:-

Motor Skill Disorder, Learning

Problems, Elementary School Children

\begin{abstract}
Background: Disorder of perceptusl motor skills (PMS) has been frequently reported in children withlearningproblems, the nature and relevance of disorder of PMS to learning disabilities are still poorlyunderstood. Studydesign and setting: A prospective longitudlinal study conducted on 195 second grade children at TaifCity. Aim of the work: To elucidate the relevance of disorder in PMS to theproblem oflearning disability. Subjects and methods: 195secondgradechildrenwereassessedfor6 PMS;coin sorting, hand dexterity, finger tapping, eye tracking, simplereaction time and hand stability at thebeginning of the academic year 2017-2018. Learning abilities were assessed by school records, teacher ratingand wide Range Achievement Test (WRAT) raw scores for readingspilling and arithmetic. At the end of theyear 2017-2018, children were looked for class repetition. Results: Subjects in the $1^{\text {st }}$ quartile (good performance) and in the 4th quartile (poor performance) of the PMS were compared fordifference in learning parameters. Highly significant differences were observed in all learning parametersbetween both groups. Multiple regression analysis revealed that PMS accountedfor highly significant amount ofvariation in variances of all learning parameters. Follow-up revealedthatsubjectswithpoorperformanceinPMS had a significantly higher incidence of class repetition; additionally, subjects with class repetition weresignificantly impaired in coin sorting, hand dexterity, and eyetracking.
\end{abstract}

Conclusion: Someof the PMSweresignificant independent variables for academic learning abilities and predictor for future leaning problems.

Copy Right, IJAR, 2020,. All rights reserved.

\section{Introduction:-}

Learning disabilities (LD), formerlyacademic skills disorders ${ }^{1}$, is one of the mostlikely causes of failure in school in otherwisecapable children ${ }^{2}$. The concept ofLD focuses onthe notion of discrepancy between a child'sacademic 
achievement and his or her apparentcapacity to learn. The term LD includes disordersin reading,mathematics, and written expressionas well as learning disorders not otherwisespecified ${ }^{1}$. Estimate studiesreported prevalencerates of LD of 5 per cent ${ }^{3}$, 3-9 percent ${ }^{4}$ and up to 28 per cent as reported by Austin et al. ${ }^{5}$ of theelementary school population. Although themajor manifestations of LD are expressed in theclassroom activities, children with LD may havecomorbid conditions such as attention deficitdisorders, depression, and neurologicalproblems ${ }^{6,7}$,As reported by Bluechardt and

Shephard ${ }^{8}$; children with LD perform poorly onso many tasks that there is almost no limits to thehypothesized underlying cognitive difficulties.

Difficulties have been reported with tasksspanning visual, motor and auditory modalitiesand including such modalities as discrimination, integration, attention and memory. Also, childrenwith LD often have their motor developmentlagging as much as two to three years behind theexpectation for their age ${ }^{9,10}$. Neurological basis ofLD include, reversed asymmetry in planumtemporale ${ }^{9}$, smaller genue of the corpuscallosum ${ }^{10}$ and symmetry in the frontal andtemporal regions ${ }^{11}$, reversed brain asymmetry ina mid-posterior brain segment corresponding tothe angular gyrus and larger splenium of thecorpus callosum ${ }^{12}$, cerebellum and centralcerebellar connection ${ }^{13,14}$, frontal and parietalcortex ${ }^{15,16,17}$. Such awide spectrum of brainabnormalities are expected to result in a widerspectrum of neuropsychologioal dysfunctionsrather than an isolatedreading-related cognitiveimpairment. Despite that nonlinguistic auditoryand visual perceptual disorders associated withLD have been extensively studied ${ }^{18,19}$,nevertheless, the area of perceptual motor skillsdisorders received very little attention, and inmany instances were described as a merecomorbid feature. Studying such relationshipcould have important contribution towards abetter understanding of the nature of thecognitive functions underlying the processes bywhich the academic abilities are achieved and thedisabilities are influenced. Thisstudy wasconducted to answer the following threequestions. First, do children with poor academicperformance differ in some non-language basedperceptual motor skills (PMS). Second, are suchskills correlated to academicparameters.Third,are children with poor PMS at a higher risk forfuture class repetition.

\section{Subjects and Methods:- \\ Subjects:}

The study population comprised of 195children in the second grade ofan elementary school in Taifcity.Their age ranged between 7 to 8 years. Theywere 110 boys,and 85 girls.

\section{Methods:-}

Academicperformance: The study wasconducted at the beginning,of the academic year $2017-2018$. The pupil's school performance wasevaluated through; A) teacher rating score; theclass teacher was asked to score each of hispupils as 1 for poor, 2 for average, 3 for aboveaverage and 4 for excellent school performance.B) schoolrecords of the midyear examination inlanguage (reading-writing) and arithmetic, andC) Wide Range Achievement Test (WRAT) rawscores for reading, spilling and arithmetic.

Perceptual motor skills (PMS): Six PMSwere evaluated; 1) finger tapping (FT) speed, 2)eye tracking (ET) speed, 3) hand stability-timeand errors (HDT and HSE), 4) hand dexterity(HD), 5) simple reaction time (RT), and 6) coinsorting (CS).

1. Finger tapping speed: The pupil was askedto press on the button of a digital counter bythe thumb of his dominant hand as fast as hecould. The number displayed at the end ofone minute was recorded as his fingertapping speed (FT).

2. Eye tracking speed: The pupil was asked todot, circles of $5 \mathrm{~mm}$ diameter arranged inlines. The direction of dotting was fromright to left. The number of dotted circles inone minute was recorded as the eye trackingspeed (ET)

3. Hand stability- time and errors: phepple-Type Stabilimeterwas used toassess hand stability .The child was requiredfrom right to left. Only the upper groovewas used in this test. When the stylus makescontact with the edge of the groove or thesurface of the inside plate a buzzer issounded and a counter counts thenumber ofcontacts. The time taken to trace the groovefrom the right to the left ends in seconds andthe number of contacts are recorded as handstability time (HST) and error (HSE). Thescore was calculated as the mean of 5 trials. 
4. Hand dexterity: a bead stringing task wasused to assess hand dexterity. The child wasinstructed tostring small pills ( $5 \mathrm{~mm}$, diameter) as fast as he could The number ofthe pills stringed in one minute wasrecordedas the hand dexterity (HD) score.

5. Simple reaction time: a graded stick was hold by the examiner hand in a verticalposition through the child's hand. He wasrequired to grasp the stick as soon as it wasreleased. The distance at which he graspedthe stick wasrecorded as his simple reaction time (RT).

6. Coin sorting task: coin sorting test was used, the child was required toinsert 50 metal discs which are different insize and thickness in 5 groups intocorresponding sites as fast as possible. Thetime in seconds needed to insert the 50 discswas measured by a stop watch. The best of two trials was recorded as his coin sorting(CS) score.

\section{Statistical Analysis:-}

All data were fed into Microsoft Excelprogram. The following statistical analyses were performed;

1. Descriptive analysis of all examinedvariables.

2. Subjects were sorteddescendingly by eachperceptual motor skill. Subject, with highest and lowest scores in each skill ( $1^{\text {st }}$ and $4^{\text {th }}$ quartiles respectively) were compared for learning parameters using two-tailed studentt-test. Significance level was set at 0.05 .

3. Incidence of class repetition in the $1^{\text {st }}$ and $4^{\text {th }}$ quartiles of each perceptual skill was lookedfor and assessed by Chi square. Significancelevel was set at 0.05 .

4. A series of multiple regression analysis (forall subjects) using the combined perceptual motor skill variables CS, HD, FT and ET asindependent variables and each of thelearning parameters as separate dependentvariables. Significance level was set at 0.01 .

\section{Resutls:-}

Data concerning number, sex, age, schoolrecords of arithmetic and reading, teacher ratingscores and WRAT raw scores of thestudied population are shown in table (1).

Data concerning the range, mean and SD ofthe studied PMS are shown in table (2).

Children were sorted by their scores in eachMPS, therefor seven sets of sorting weregenerated (one set for each skill). Children in theupper quartile and in the lower quartile $(n=48)$ were compared as regard their scores in eachlearning parameters. Children with low and highscores in HS (time and errors) and RT did notsignificantly differ in any of the learningparameters. Children in thefirst quartile (higherperformance) of the CS, HD, FT and ET were significantly higher than children in the fourth quartile (lower performance) in all learningparameters detailed data are shown in tables (3-6). Following up children until the end oftheacademic year showed that that 25 (13\%) children'had class repetition in one or two classes.Children with class repetition were significantlyimpaired in CS, $\mathrm{HD}$, and ET tests compared tochildren who passed the academic yearsuccessfully, there were no significantdifferences between the groups as regardHS orsimple RT scores, table (7). Moreover, thenumberof children with class repetition werehigher in the fourth than first quartiles of the allPMS sorting sets, howeversignificant difference were observed in the ET set $(\mathrm{p}<0.0001), \mathrm{HD}(\mathrm{p}<0.001)$ and CS set ( $\mathrm{p}<0.01)$. Detaileddata areshown in table (8). Multiple regression analyseswere carried out between the combinedperceptual motor variables (after exclusion of theinsignificant variables (HS and RT) asindependent variables and each of thelearningparameters as separate dependent variables. The results showed that MPS significantly $(\mathrm{P}<0.0001)$ accounted for $19-37 \mathrm{o} / \mathrm{o}$ of variation invariances of the learning parameters, detaileddata are shown in table (9).

Table 1:- Age sex and learning parameters scores of the studied population, $n=195$ (base-line assessment).

\begin{tabular}{l|l} 
Age range & $82-100$ months \\
Mean age (SD) & $86(3.5)$ \\
Number of males & 110 \\
Number of females & 85 \\
Total number & 195 \\
School record (arith) & $12-18$ \\
School record (lang) & $12-18$ \\
Teacher rating & $1-4$ \\
\hline
\end{tabular}


Table 2:- Perceptual motor skills (PMS) scores of the studied population, $\mathrm{n}=195$

\begin{tabular}{|l|l|l|}
\hline PMS & Range & Mean (SD) \\
\hline Finger tapping speed & $43-123$ & $34(12)$ \\
Eye tracking speed & $30-65$ & $42(8)$ \\
Hand stability - error & $1-9$ & $3(1)$ \\
Hand stability - time & $1-6$ & $4(2)$ \\
Hand dexterity & $3-17$ & $10(4)$ \\
Simple reaction time & $13-32$ & $23(5)$ \\
Coin sorting & $20-120$ & $67(11)$ \\
\hline
\end{tabular}

Table 3:- Difference in learning parameters between children with high and low coin sorting scores $1^{\text {st }}$ and $4^{\text {th }}$ quartile respectively $n=48$ in each group.

\begin{tabular}{|l|l|l|l|l|l|l|}
\hline & SRR & SRA & TR & WRAT-S & WRAT-A & WRAT-R \\
\hline $1^{\text {st }}$ quartile & $16.2(4.2)$ & $17.3(3.5)$ & $3.2(0.9)$ & $32.2(9.1)$ & $23.2(1.4)$ & $42.7(15.8)$ \\
$4^{\text {th }}$ quartile & $12.6(6.3)$ & $13.4(5.6)$ & $2.2(1.1)$ & $27.6(1.0)$ & $21.5(3.8)$ & $31.0(8.0)$ \\
Significance & $\mathrm{P}<0.01$ & $\mathrm{P}<0.0001$ & $\mathrm{P}<0.0001$ & $\mathrm{P}<0.01$ & $\mathrm{P}<0.01$ & $\mathrm{P}<0.0001$ \\
\hline
\end{tabular}

SRR; school-record for reading ,SRA; school record arithmetic, TR; teacher rating.WRAT-Sspelling,WRATA;WART arithmetic, WRAT-R; WART reading scores.

Table 4:- Difference in learning parameters between children with high and low hand dexterity scores $1^{\text {st }}$ and $4^{\text {th }}$ quartile respectively.

\begin{tabular}{|l|l|l|l|l|l|l|}
\hline & SRR & SRA & TR & WRAT-S & WRAT-A & WRAT-R \\
\hline $1^{\text {st }}$ quartile & $17.8(2.8)$ & $17.3(3.5)$ & $3.5(0.9)$ & $35.9(11)$ & $23.4(1.7)$ & $41.6(11)$ \\
$4^{\text {th }}$ quartile & $11.4(6.3)$ & $12.5(5.9)$ & $1.9(0.9)$ & $25.4(8.7)$ & $20.8(3.6)$ & $29.9(11.8)$ \\
Significance & $\mathrm{P}<0.0001$ & $\mathrm{P}<0.0001$ & $\mathrm{P}<0.0001$ & $\mathrm{P}<0.0001$ & $\mathrm{P}<0.0001$ & $\mathrm{P}<0.0001$ \\
\hline
\end{tabular}

SRR; school-record for reading SRA; school record for arithmetic, TR; teacher rating score, WRAT-S;WRATspelling,WRAT-A;WART arithmetic, WRAT-R; WART reading scores.

Table 5:- Difference in learning parameters betweenchildren with high and low finger tapping scores, $1^{\text {st }}$ and $4^{\text {th }}$ quartile respectively $n=48$ in each group.

\begin{tabular}{|l|l|l|l|l|l|l|}
\hline & SRR & SRA & TR & WRAT-S & WRAT-A & WRAT-R \\
\hline $1^{\text {st }}$ quartile & $15.2(4.7)$ & $16.9(4.1)$ & $3(1)$ & $33.4(12.7)$ & $23.3(2)$ & $37(12.4)$ \\
$4^{\text {th }}$ quartile & $12.6(6.4)$ & $13.1(5.8)$ & $2.2(1)$ & $26(8.4)$ & $21(3.6)$ & $31(11)$ \\
Significance & $\mathrm{P}<0.05$ & $\mathrm{P}<0.001$ & $\mathrm{P}<0.001$ & $\mathrm{P}<0.001$ & $\mathrm{P}<0.001$ & $\mathrm{P}<0.01$ \\
\hline
\end{tabular}

SRR; school-record for reading SRA; school record for arithmetic, TR; teacher rating score, WRAT-S;WRATspelling,WRAT-A;WART arithmetic, WRAT-R; WART reading scores.

Table 6:- Difference in learning parameters between children with high and low Eye tracking scores, $1^{\text {st }}$ and $4^{\text {th }}$ quartile respectively.

\begin{tabular}{|l|l|l|l|l|l|l|}
\hline & SRR & SRA & TR & WRAT-S & WRAT-A & WRAT-R \\
\hline $1^{\text {st }}$ quartile & $17.1(3.3)$ & $17.4(3.7)$ & $3.3(0.8)$ & $35.3(10.2)$ & $23.2(1.6)$ & $42.1(13.7)$ \\
$4^{\text {th }}$ quartile & $12(6.5)$ & $13.6(6.1)$ & $2.2(1)$ & $24.6(7.7)$ & $21.2(3.1)$ & $30.7(12)$ \\
Significance & $\mathrm{P}<0.0001$ & $\mathrm{P}<0.0001$ & $\mathrm{P}<0.0001$ & $\mathrm{P}<0.0001$ & $\mathrm{P}<0.0001$ & $\mathrm{P}<0.0001$ \\
\hline
\end{tabular}

SRR; school-record for reading SRA; school record for arithmetic, TR; teacher rating score, WRAT-S;WRATspelling,WRAT-A;WART arithmetic, WRAT-R; WART reading scores.

Table 7:- perceptual motor skills in children with and without class repetition .

\begin{tabular}{|c|c|c|c|c|c|c|c|}
\hline & $\mathbf{C S}$ & HD & FT & ET & SRT & HSE & HST \\
\hline Children With CR $(\mathrm{N}=25)$ & $303(94)$ & $6(2)$ & $136(33)$ & $38(10)$ & $29(7)$ & $4(2)$ & $2(1)$ \\
\hline Children Without CR $(n=170)$ & $245(53)$ & $10(3)$ & $145(30)$ & $51(13)$ & $27(8)$ & $4(2)$ & $2(2)$ \\
\hline Significance & $\mathrm{P}<0.0001$ & $\mathrm{P}<0.0001$ & $\mathrm{NS}$ & $\mathrm{P}<0.0001$ & NS & $\mathrm{NS}$ & NS \\
\hline
\end{tabular}

CS; coin sorting, HD; hand dexterity, FT; finger tapping, ET; eye tracking ,SRT; simple reaction time; SE; hand stability-errors, HST; hand stability time, CR; class repetition. 
Table 8:- Difference in incidence of class repletion between children with high and low scores of PMS, $1^{\text {st }}$ and $4^{\text {th }}$ quartiles respectively..

\begin{tabular}{|l|l|l|l|l|l|l|l|}
\hline & CS & HD & FT & ET & SRT & HSE & HST \\
\hline $1^{\text {st }}$ quartile & 1 & 0 & 6 & 0 & 5 & 5 & 5 \\
$4^{\text {th }}$ quartile & 12 & 15 & 11 & 14 & 9 & 8 & 7 \\
Significance & $\mathrm{P}<0.01$ & $\mathrm{P}<0.001$ & NS & $\mathrm{P}<0.0001$ & NS & NS & NS \\
\hline
\end{tabular}

CS; coin sorting, HD; hand dexterity, FT; finger tapping, ET; eye tracking SRT; simple reaction time; HSE; hand stability-errors, HST; hand stability time.

Table 9:- Multiple regression analysis of the PM skills and learning parameters.

\begin{tabular}{|l|l|l|l|l|l|l|}
\hline & SRR & SRA & TR & WRAT-S & WRAT-A & WRAT-R \\
\hline F & 18.4 & 16.1 & 27.9 & 14.7 & 12.0 & 11.0 \\
R2 & 0.28 & 0.25 & 0.37 & 0.24 & 0.20 & 0.19 \\
Significance & $\mathrm{P}<0.0001$ & $\mathrm{P}<0.0001$ & $\mathrm{P}<0.0001$ & $\mathrm{P}<0.0001$ & $\mathrm{P}<0.0001$ & $\mathrm{P}<0.0001$ \\
\hline
\end{tabular}

SRR; schoolrecord for reading SRA; school record for arithmetic, TR; teacher rating score, WRAT-S;WRATspelling,WRAT-A;WART arithmetic, WRAT-R; WART reading scores.

\section{Discussion:-}

Learning disability is one of the mostcommon causes of school failure amongelementary school population. Basically thecondition includes disorders of reading,mathematics, and writing either in isolation ormost commonly in combination Despite thatimpairment in academic skills constitute theprimary cause of referral for assessment andintervention, children with learning, disabilityoften present with deficits in some other non-languagebased skills. As for example perceptualmotor functions involving the hand and eye andperceptual auditory and visual information ${ }^{17}$.

This work addresses the question whetherdeficits in some perceptual motor skills (PMS)are related to the child's academic skills or theyconstitute a comorbid feature that is unrelated tothe child's learning abilities. Our results drawnfrom a longitudinal study of about 195 second graders indicated that children with poorperceptual motor performance had significantimpairment in many of school performanceparameters as indicated by their lower scoresschool records, teacher rating and WRATreading, spelling and arithmetic.

Consistent with our results are the finding ofSnow ${ }^{18}$, who reported significant differencebetween subgroups of subjects with LD in visual-motorintegration, motor speed and tactileintegration and also with findings of Wilkes etal. andLahane $\mathrm{S}$ et al. ${ }^{20}$ that about one fifth of agroup of first grade children with LD haddisorders of motor functions including bodycoordination and finger-eye coordination.Additionally; similar findingswere reported by Lasauxet al. ${ }^{21}$, Goswami U -etal. ${ }^{22}$, Mogasale VV. ${ }^{23}$, Muzahid Aet al ${ }^{24}$. In a trial to answer thequestion whether abnormalities in PMS arerelated to the child's learning abilities, we lookedfor correlation between the children's learningparameters and their scores in PMS, also wefollowed-up our children until the end of theacademic year and looked for any predictivevalue of poor performance on PMS and the riskfor class repetition. Our results provide someevidence that PMS are significantly related andcould affect academic learning. First, childrenwith low scores in CS, HD, FT, and ET hadsignificantly lower scores in all learningparameters. Second, those children also hadsignificantly higher risk for one or more classrepetition Additionally, children with classrepetition were significantly impaired in CS HD and ET but not in the other MPS. Third, multipleregression analysis of the combined variables ofthe MPS against each of learning parametersshowed that MPS significantly $(\mathrm{P}<0.0001)$ accounted for $19-37 \%$ of variation in variancesof all learningparameters. These findingsindicate that at least some of these MPSinfluence the neural processes by whichacademic performance is achieved. To explainthe relationship between MPS and academicperformance, we suggest three differentpossibilities. First, academic performance utilizessome other cortical connections, in addition tothe classical language areas, which are mediatingMPS. In support of this possibility are thefindings reported by Nicolson et al. ${ }^{18}$ indicatinginvolvement of cerebellum and central cerebellarconnections, which are crucial for integratingfine and complex movement of the hands, fingersand eyes, in reading and other reading relatedtasks. Moreover, fMRI studies demonstrated thatregions of the parietal lobes, which are importantbrain structures involved in learning disabilities, have consistently been involved in motor skilllearning and fronto-parietal interaction have beenemphasized, also as reported by Cavalli $\mathrm{E}$ et $\mathrm{al}^{25}$, parietal, supplementary motor area andcerebellum are involved in hand and finger movernents ${ }^{26}$. Furthermore, cerebellar activitieshave observed in several studies and theactivation pattern in non-motor skill learning issimilar to 
that of motor skill learning ${ }^{27}$. Second,PMS utilize neural connections that have beenprototypical for academic skills. In support ofthis point of view, is the fact that reading andother reading related skills, contrary to othercognitive skills, are only acquired throughteaching process known as education providedby others, an individual cannot learn how to readand write by watching and imitating othersubjects. This implies that reading and writing isnot a primary brain function. So, existence of aspecific brain connection primarily andexclusively assigned for reading is doubtful, themore reasonable is that such connections couldhave been evolved from some other more basic functional networks and established as a result of neural plasticity and synaptic reorganizationaffected by the process of education. Third,owing to the extensive neural networksubserving readingand other learning relatedskills, lesions in such connections are more likelyto result in a wide spectrum of perceptual andcognitive impairment rather than an isolatedreading disorder. In support ofthis suggestion isthe observation ofPatterson et al. ${ }^{28}$, that readingdisorder rarely if ever occurs in isolation, thus, disorder of perceptual motor skills and learningdisabilities could represent parallel maturationallags. In conclusion, academic performance in theearly school grades is influenced by the child'sperformance in some non-academic skills such asperceptual hand and finger movements. Theneurocognitive spectrum involved in learningdisabilities is much more wider than expected from the current definition of the problem.Impairment of PMS could have an important role in determining the extent and severity of thelearning problem. Assessment of PMS could behelpful in identification of the children at highrisks for LD. Finally, dealing with non-languagerelated activities such as PMS might beconsidered in remediation programs for childrenwith learning disabilities.

\section{References:-}

1. American Psychiatric Association. DiagnosticCriteria from DSM-IV. Published by AmericanPsychiatricAssociation , $1400 \mathrm{t}<$ street, N. W., Washington DC 20005,1994.

2. Levy HB, Harper CR, Weinberg WA. A practical approach to children failing in school. PediatricClinic of North America, 39(4):895-928, 1992.

3. Lyon CR. Learnidisabilities. Future Child 6(1):54-76,1996.

4. Lehmkuhle 5, Garazia RP, Turncr L, Hash T,Baro JA. A defective visual pathway in children with reading disability. The NewEnglandJournal of Medicine. 328(14): 989-96. 1993.

5. Austin S, Cherkes-Julkowski M, Ford J.Screening for ìearning disabilities inpreadolescents using psychosocial disabilityrnarkers- a pilot study. Annals of Epiclerniology,I 0(7): 483, 2000.

6. Johnson DJ. An overview of learning clisabilíties:psychoeducationalperspectives. J our.nal of ChildNeurology, 10 Suppl t:t2-5,1995

7. 7-Padhy SK1, Goel S2, Das SS3, Sarkar S4, Sharma V3, Panigrahi M5.7- Coutinho MJ, Oswald DP, Best AM. The influence of sociodemographics and gender on the disproportionate identification of minority students as having learning disabilities. Remedial and Special Education. 2002;23(1):49-59

8. 8-Bluechardt M, Shephard RJ. Motor performanceimpairment in students with leamingdísabilities:influence of gende,r and body build,. SportMedicine, Training and Rehabilitation, 7;133_t40,1996.

9. 9-Wright BA, Bowen RW, Zecker SC .Nonliguistic perceptual deficits associated with reading and language disorders,Neurology, 10 (a0): 482-486,2000.

10. 10-Rosenberg J, Pennington BF, Willcutt EG, Olson RK. Gene by environment interactions influencing reading disability and the in-attentive symptom dimension of attention deficit/hyperactivity dis-order. J Child Psychol Psychiatry. 2012;53:243-51.11.

11. Cantell MH, AhonenTp and Smyth MM.Clumsiness in adolescence: Educational motorand social outcomes of motor delay detected at 5years, Adapt Phys_Acreuart, 1l:115_129,1994.(cited by Bluechardr et al, I 996).

12. 12- Beaton AA. The relation of planunrtemporaleasymmetry and morphology of the ,corpuscallosum to handedness, gender änddyslexiå: areview of the evidence. Brain and Language,60(2):255-322, 1997.

13. 13-Temple CM, Jeeves MA, Vilarroya OO. Readingincallosal agenesis, Brain and Language,39(2):253s3,1990.

14. 14- Kohli A, Malhotra S, Mohanty M, Khehra N, Kaur M. Specificlearning disabilities in children: deficits and neuropsychologicalprofile. Int J Rehabil Res. 2005;28:165-9.15.

15. 15-Hynd GW, Hall J, Novey ES, E.liopulos D, BlackK, Gonzalez JJ, Edmonds JE. Cohen M.Dyslexia and corpus callosum morphology.ArcheivesNeurology, 52(1): 32-8, 1995.

16. 16-Duara R, Kushch A, Gross-Glenn K, BarkerWW, Jallad B, Pascal S, Loewenstein DA,

17. 17-Sheldon J, Rabin M, Levin B, et al.Neuroanatomicdifferencesbetweendyslexic andnormal readers on magnatic resonance imagingscans. Archives Neurology 48(4):41 0-6,1 99 I .

18. 18-Nicolson RI, Fawcett AJ, Berry EL, Jenkins 1H,Dean P, Brooks DJ. Association of abnormalcerebellar activation with motor leamingdifficulties in dyslexic adults, The Lancet,353(9 I 65): | 662-7, 1999. 
19. 19-Husadin M, Visuospatial and visuomotorfunctions of the posterior-patietal lobe, ln SteinJF, ed. Vision and Visual dyslexia. Boca Raton:

20. CRC Press. PP 12-43,1991.

21. 20-Lahane S, Shah H, Nagarale V, Kamath R. Comparison of self-esteem and maternal attitude between children with learning dis-ability and unaffected siblings. Indian J Pediatr. 2013;80:745-9.16.

22. 21-Lesaux NK, Lipka O, Siegel LS. Investigating cognitive and linguistic abilities that influence the reading comprehension skills of children from diverse linguistic backgrounds. Reading and Writing. 2006;19:99-131

23. 22-Goswami U., Wang H.-L.S., Cruz A., Fosker T., Mead N., Huss M. Language-universal Sensory Deficits in Developmental Dyslexia: J. Cogn. Neurosci. 2011;23:325-337

24. 23-Mogasale VV, Patil VD, Patil NM, Mogasale V. Prevalence ofspecific learning disabilities among primary school children in asouth Indian city. Indian J Pediatr. 2012;79:342-7.17.

25. 24-Muzahid Ali, A.S.M. Sarwar.Prevalence of Dyslexia in Primary School in Dhaka: Its Effects on Children's Academic and Social Life.International Journal of Advanced Research (2015), Volume 3, Issue 12, 1327 1331.

26. 25- Cavalli E., Casalis S., Ahmadi A.E., Zira M., Poracchia-George F., Colé P. Vocabulary skills are well developed in university students with dyslexia: Evidence from multiple case studies. Res. Dev. Disabil. 2016;51-52:89-102

27. 26-Wiseheart R., Altmann L.J.P. Spoken sentence production in college students with dyslexia: Working memory and vocabulary effects. Int. J. Lang. Commun. Disord. 2017:1-15

28. 27-Toffalini E., Giofrè D., Cornoldi C. Strengths and Weaknesses in the Intellectual Profile of Different Subtypes of Specific Learning Disorder: A Study on 1049 Diagnosed Children. Clin. Psychol. Sci. 2017;5:402409

29. 28- Törö KT, Miklósi M, Horanyi E, Kovács GP, Balázs J. Reading Disability Spectrum: Early and Late Recognition, Subthreshold, and Full Comorbidity. J Learn Disabil. 2018;51:158-167. 